Revista Iberoamericana, Vol. LXXIX, Núm. 243, Abril-Junio 2013, 559-575

\title{
LITERATURA AFRO-FEMENINA EN LA REPÚBLICA DOMINICANA. ¿UNA INDEFINITUD QUE LA DEFINE?
}

\author{
POR \\ DAWn Duke \\ University of Tennessee
}

Este trabajo explora las polémicas temáticas que articulan el constructo de la identidad afro-femenina en la literatura dominicana, especialmente se centra en el estudio de la propuesta intelectual de la escritora Aída Cartagena Portalatín. En nuestra investigación, dialogamos también con textos de otras escritoras e intelectuales tales como Sherezada (Chiqui) Vicioso, Ylonka Nacidit-Perdomo, Celsa Albert Batista y Pura Emeterio Rondón las cuales enfocan la condición afro-femenina en sus aspectos actuales. Tales voces nos ofrecen la oportunidad de explorar manifestaciones de una Negritud literaria la cual, tomada como un posicionamiento ideológico, seguramente entra en choque con la identidad nacional dominicana, famosa por su espíritu generalizado de resistencia a lo etno-africano. Confirmamos que de hecho hay un corpus limitado de poemas y narraciones que podríamos incluir dentro de la categoría de literatura negra hecha por escritoras comprometidas. Corroboramos también que el acto de declararse "escritora afro-dominicana" nunca ha sido un camino favorable a estas escritoras, al mismo tiempo que sin duda, en su manera estética, cada una se refiere a las raíces africanas. Trabajar la intersección raza, género y literatura implica traer a la mesa de discusión la idea de conciencia. Implica identificar a escritoras negras que adoptan posiciones como productoras afro-femeninas en el contexto nacional dominicano, que construyen su voz desde su herencia, y que la hacen surgir en su producción en forma de ensayo, poema, cuento, novela y otros géneros. Esta producción es conocida por una actitud cuestionadora, un posicionamiento interrogativo, una inquietud frente a este rechazo de las raíces africanas, principio que el pueblo heredó y que se reforzó enfáticamente durante el trujillismo. La trayectoria histórica de la nación dominicana, si por un lado les ha permitido la oportunidad y el privilegio de ser escritoras y la distinción de ser letradas, por otro lado, al mismo tiempo, esta misma trayectoria ha dificultado plenas manifestaciones de orgullo de la condición de Negritud. No hay duda, sin embargo, que las presiones nunca han impedido que la mujer dominicana que escribe se exprese sobre cuestiones de historia, el problema de la mujer, la educación, la cuestión étnica y el supuesto "problema" de Haití. 
Hay buenos registros sobre la contribución de la mujer dominicana en la historia y la literatura del siglo XIX y Xx. Las experiencias son muy diferentes debido a la dinámica conflictiva entre los dos países que ocupan la isla. Elénfasis dominicano en el sentimiento de pro-independencia irremediablemente se traducía en un posicionamiento anti-haitiano lo que, a la vez, tenía implicaciones para cualquier manifestación o agenda relacionada con un discurso de la africanidad caribeña. Está plenamente registrada la participación de la mujer hispano-dominicana y afro-dominicana en la acción y el sentimiento nacionalistas. En las primeras décadas del siglo XIX, el deseo de independizarse de Haití impidió la posibilidad de problematizar, apoyar, ver, o contemplar la posición del negro en la sociedad. De hecho el negro dominicano se encontraba en un dilema, ya que el supuesto enemigo, el haitiano, cuyo color y cultura comparte, es el mismo que lo estaba liberando de su estado esclavizado. En este caso, los intereses nacionales se sobrepusieron a la condición humana subyugada del negro dominicano borrando la posibilidad de la perspectiva y de la voz del negro en la historia y en la cultura. Esta herencia conflictiva diseñó el camino literario que contemplamos hoy.

El valor de la participación femenina asegura su lugar dentro del discurso de la nación y dentro del actual espíritu de patriotismo en la medida en que tal valor consigue mantener distancia entre una subjetividad negra que pueda corresponder o asociarse con el enemigo haitiano. Este contexto dificulta el desarrollo de una historicidad textual que demuestre una apreciación histórica específica de la mujer negra. Lo que se puede observar es un discurso histórico fijado en la contribución de la mujer en las luchas independentistas y anti-imperialistas dentro del cual sí se encontrarían referencias a figuras afro-femeninas que lucharon fuertemente y que murieron por tales causas. Los textos de Lebrón de Anico, La mujer en la gesta heroica de la Independencia Nacional (2000); y de Álvarez, Mujeres del 16 (2005), ilustran el argumento que confirma la valentía y el compromiso de la mujer dominicana que luchó al lado del hombre para restaurar la dignidad nacional al independizar al país de la humillante colonización haitiana en 1844. Textos tales como Mujeres de febrero de Solano y Ortiz Gómez, una publicación de la Secretaría de Estado de la Mujer, confirman el encuadramiento del inicial espíritu feminista dentro del propósito mayor del Estado. Podemos apreciar la distinción entre tales luchadoras y la mujer negra esclavizada de la época, que habría estado más interesada en los ideales abolicionistas que acompañaban la ocupación haitiana y que, por lo tanto, difícilmente apoyaría los intereses pro-independentistas de sus compatriotas blancas dominicanas. En una atmósfera de agresión y guerra y dentro de un espíritu nacionalista de preservación de la soberanía nacional contra los invasores haitianos negros, no habría sido posible construir a largo plazo una actitud receptiva de una cultura afro-dominicana.

Entre 1850 y 1950 el camino hacia la modernización no incluía un favorecimiento de la Negritud. La escasez de iconos negros femeninos en el imaginario histórico y el vigoroso sentimiento anti-haitiano (y por eso mismo, anti-negro) durante el período

Revista Iberoamericana, Vol. LXXIX, Núm. 243, Abril-Junio 2013, $559-575$
ISSN 0034-9631 (Impreso) 
final de la colonia hasta hoy han moldeado el camino histórico. Al mismo tiempo, este distanciamiento no implicaba una ausencia total de heroínas negras en el siglo xx; las figuras de Nieves Sierra "Doña Chucha" (nacida en 1914), Florinda Soriano conocida como Mamá Tingó (1920-1974), y Petronila Angélica Gómez (1883-1971), representan buenos ejemplos. Esta última sobresalía en un medio privilegiado dominado por la mujer hispano-dominicana en aquel momento del inicio del feminismo. De modo general, la preferencia era privilegiar la iniciativa de todas las mujeres para defender la soberanía nacional. Tampoco es una discusión que se detiene en apenas un acontecimiento histórico. Los momentos históricos más destacados fueron la lucha por la independencia, el movimiento de resistencia a la dictadura de Trujillo y la invasión norteamericana de 1965:

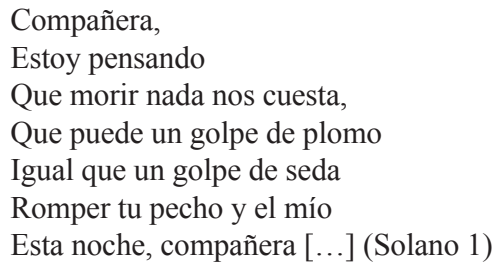

En 1965, “Las mujeres también hicieron abril” era el lema del cual la nación también podía enorgullecerse porque confirmaba un sentimiento general frente a la invasión estadounidense del territorio dominicano y el odio y la fuerte resistencia que generó este acontecimiento. Una vez más podemos señalar una divergencia de opinión entre las dos naciones frente al problema estadounidense. El fuerte rechazo a las ambiciones imperialistas norteamericanas en territorio dominicano contrastaba con las alianzas establecidas entre el régimen duvalierista y el Estado norteamericano. "1965 las mujeres también hicieron abril" (Solano) inscribe en la historia la lista de mujeres dominicanas blancas y negras que murieron luchando contra los invasores. La figura martirizada de la afro-dominicana Yolanda Guzmán, por ejemplo, aparece al lado de otras tantas mujeres, sin necesidad de distinguirla por ser negra. ${ }^{1}$

Bankay, Rodríguez Guglielmoni y Kerman enfatizan la importancia de situar un análisis de la literatura femenina dominicana dentro de la historia nacional. Confirman una expansión en la producción como un fenómeno reciente, asociado con la segunda mitad del siglo xx y reiteran cambios aún más recientes en el status de la producción femenina dentro del canon dominicano. Rodríguez Guglielmoni y Kerman presentan el caso de Portalatín cuyo mayor reconocimiento vino póstumamente. Según éstas, hay que elaborar otros criterios para poder apreciar la postura artística de esta escritora.

1 Consultar Solano (5). También el artículo de periódico "Dominicanas meritorias: doce calles con sus nombres en un homenaje permanente".

Revista Iberoamericana, Vol. LXXIX, Núm. 243, Abril-Junio 2013,
ISSN 0034-9631 (Impreso) 
Detenerse apenas en lo ideológico-político sería necesario pero a la vez incompleto: "And yet, feminism has taught that the personal is political. Is Nacidit-Perdomo's song a song of Love? Is it to ART itself? From Emma Goldman to Che Guevara to bell hooks, thinkers about revolution have said that to love is the ultimate, most difficult and revolutionary act" (Rodríguez Guglielmoni y Kerman 15-16). Vallejo acompaña tal crítica al afirmar que "la realidad de los sucesos históricos: invasión, revolución, urbanización, aburguesamiento, lleva a una literatura comprometida con su realidad sociopolítica circundante"(91). La perspectiva letrada, de hecho, debe abrirse para poder entender el medio intelectualizado alrededor del tema de la mujer afro-dominicana que escribe hoy. Aquí se da prioridad a las que aparentan cierta conciencia de la Negritud y las que articulan tal conciencia a partir de lo literario pero no exclusivamente.

En la literatura no hay una conexión espontánea y orgullosa entre raza, género y nación. Al mismo tiempo hay un nexo celebratorio entre la mujer y la nación. El componente "raza" resulta más complejo por implicar una intención de valorar la contribución específica de afro-dominicanas, un gesto que, hasta ahora en el espacio nacional, no se ha producido de forma separada y unívoca. Compilaciones como La mujer dominicana (1980), Perfil de la mujer dominicana ayer y hoy (1992), "Dominicanas meritorias: doce calles con sus nombres en un homenaje permanente" (El País, 2003) y Evas terrenales (2000) aseguran el homenaje oficial y constante en el ámbito del Estado a todas las profesionales y escritoras. No hay una compilación específica para la mujer negra profesional o escritora. Construir una noción de la producción afro-femenina se demuestra estrecha si se intenta hacerla divorciada del contexto de la construcción letrada de la nación. Al asumir la posición de autoridad, el discurso de Nación choca con la historicidad negra; la población negra en la historia dominicana sufrió una exclusión arbitraria de los beneficios otorgados a los que formaban parte de la nación. El resultado es una historia separada, silenciada, poco estudiada. La población negra local, con limitados recursos y ningún acceso a la educación sólo consiguió comparecer en el siglo xx, aun así en números muy limitados. El surgimiento de figuras letradas dependía de la posibilidad familiar de lograr cierto status socioeconómico para poder facilitar la formación y la escolaridad familiar. Claro, primero lo consiguieron los hombres, mucho después las mujeres. También hoy, ya conocemos las figuras femeninas que sobresalieron entonces. El resultado es que hablar del tema, de hecho, crea cierta polémica porque no hay posibilidad de identificar una línea de producción literaria obvia y clara hecha por mujeres negras como en otras partes del Caribe. La constante fricción entre la República Dominicana (nación hispánica y mestiza) y Haití (nación mulata y negra) no ha facilitado la posibilidad de un pensamiento literario-cultural favorable a la noción de una negrura celebratoria. ${ }^{2}$

2 Howard, Roberts y Stevens-Acevedo problematizan el tema del reconocimiento de la herencia negra en la historia y la literatura dominicana.

Revista Iberoamericana, Vol. LXXIX, Núm. 243, Abril-Junio 2013,
ISSN 0034-9631 (Impreso) 
“De qué color es la literatura dominicana?”, esta pregunta de Rondón da inicio a su crítica literaria sobre la cuestión de identidad y la literatura nacional (135-154). Esta especialista parece defender el deseo quisqueyano de no definirse con exactitud. Afirma que hay tantas variedades que "preferimos no fijar ninguno de ellas" (135). Esta perspectiva relativa frente a la identidad nacional según Rondón es un dilema caribeño y encuentra su justificación en el deseo de no simplificar demasiado el contexto local. Al mismo tiempo, Rondón reconoce el peligro al indicar que en el medio nacional se vende tranquilamente la hipótesis de que en la República Dominicana no hay negros, como confirma una perspectiva incompleta. Rondón completa esta idea al afirmar que no hay negros, tampoco hay blancos. Añade un esclarecimiento: "Desde el punto de vista racial hay una diversidad palpable, reconocible, pero difícil de fijar material o conceptualmente, se escapa" (136). Defiende el proceso de mestizaje, posiciona la experiencia históricoracial dominicana en oposición a la haitiana en cuyo territorio, según ella, se visualiza tres grupos radicalmente marcados - negros, mulatos y blancos-cada uno con sus intereses clasistas, raciales y políticos. Insiste en el estado no homogeneizado del mestizaje dominicano, al mismo tiempo que parece desear disminuir el efecto de la esclavitud sobre el negro dominicano, argumentos que confirman el estilo unificador del discurso estatal sobre el tema. Rondón se inclina hacia la noción de una esclavitud fraternal, un concepto frecuentemente usado para justificar el argumento de una esclavitud benevolente, más suave en el mundo hispano, que contrasta con la esclavitud en la colonia francesa vecina. El estilo operacional hispano resultó en "el hibridismo cultural y la complejidad racial característicos del Caribe [y] encuentran en las expresiones culturales dominicanas una muy clara expresión" (139). Tales convicciones histórico-culturales forman la base del abordaje teórico frente a la cuestión de la identidad negra. Afirmarse negro nunca se expresa directamente, se lo argumenta, se lo negocia y la literatura acompaña tal perspectiva. Al mismo tiempo podemos observar las contradicciones que existen entre esta elaboración teórica y la actual condición sociocultural precaria de la mujer negra (haitiana, dominicana, y dominico-haitiana) en la sociedad.

Roberts, Adams y Fenwick han identificado a las escritoras dominicanas que producen una literatura que se caracteriza como afrohispánica y caribeña. La justificación ha sido una producción mayoritariamente poética que explora la condición femenina en todas las esferas, lo que sirve de criterio-base para justificar la inclusión de Aída Cartagena Portalatín, Ángela Hernández Núñez, Aurora Arias, Marianela Medrano, Sherezada (Chiqui) Vicioso, Ida Hernández Caamaño, Jeannette Miller, Ylonka Nacidit-Perdomo, Carmen SánchezAponte, Dulce Ureña, Catharina Vallejo, Ligia Minaya, Emilia Pereyra y Emelda Ramos. La Caribeñidad, la Negritud, y el Feminismo sirven para analizar esta estética que demuestra una gran conciencia, una preocupación con esta condición de ser en un espacio que siempre ha rehusado incorporar dentro de su discurso de nación politizado, un valor en defensa de un mundo afro y de la mujer. Se puede confirmar tal apoyo en el mundo de la literatura femenina y en la esfera del activismo afro-feminista.

\footnotetext{
Revista Iberoamericana, Vol. LXXIX, Núm. 243, Abril-Junio 2013, 559-575 ISSN 0034-9631 (Impreso) ISSN 2154-4794 (Electrónico)
} 
Esta producción femenina afirma una subjetividad oriunda de un proceso histórico complejo, fruto de una identidad heterogénea. En la medida en que escriben, re-crean un estado de ser específico y múltiple. La literatura en sí obligatoriamente asume una posición de confrontación por ser un trabajo en contra, un proceso contrario a la herencia femenina de un silencio, de una invisibilidad histórica y de una subordinación socioeconómica que aún sigue dejando rastros y consecuencias.

\section{La Negritud de Aída: en homenaje a Teodora y Micaela}

En esa poesía de la negritud encontré una mística y una magia, un ámbito cultural inalienablemente negro. En ella estaba el que a golpes de intuición, objetividad y realismo imaginativo hería el parche para ir al encuentro del dios de fuego en cuya hoguera se consumía el hombre negro, sin ojos, aplastado por el blanco. (Portalatín, Culturas africanas 17)

Los ensayos de Portalatín en Culturas africanas rebeldes con causa son la prueba palpable del descubrimiento y la apreciación de la autora por la Negritud como una filosofía cultural africana y caribeña. Un "camino a la Negritud" (53), es la frase que usa para dar cuenta de su descubrimiento de las luchas y el trauma en África, su contacto personal con los activistas, mártires, políticos y escritores africanos más famosos de los años sesenta y setenta del siglo pasado. El espíritu testimonial y la apreciación politizada visibles en estos ensayos son importantes si consideramos la potencial influencia nacional de esta poeta dominicana. Portalatín (1918-1994) ocupa la posición de la figura femenina que tiene el mayor respaldo en el ámbito literario nacional; según Cocco de Filippis es la escritora dominicana más importante del siglo xx ("Aída Cartagena" 191). Poeta, ensayista, narradora, historiadora y educadora, Portalatín se registra como la escritora nacional más prolífica de todos los tiempos y la que, en sus obras, ha registrado, sin duda, una producción amplia y diversificada en enfoque e interés. Al inicio de su carrera se dedicaba a la poesía, actualmente, se la describe como una de los poetas que "militó en la agrupación La Poesía Sorprendida que reunía a los poetas mas elitistas del país de los años 40 y 50" (Gutiérrez 46). Muy conocida por su novela Escalera para Electra que la llevó a ser finalista del Premio Biblioteca Breve (Seix Barral) en 1969, hasta hoy sigue como la escritora más estudiada y antologizada. Fenwick describe a Portalatín como una de las hermanas más elocuentes de Calibán (xxiii-xxiv). Queda en la memoria literaria caribeña como una de las escritoras contemporáneas de larga carrera que tuvo además el coraje de desarrollar una perspectiva histórica y feminista en su obra. De hecho, es una de las voces de mayor extensión del siglo xx. Cuando murió en 1994 era ya una figura representativa de la vanguardia en la literatura dominicana y caribeña contemporáneas.

Sus ensayos en Culturas africanas reconocían la propuesta política de Senghor, Damas y Césaire: "La Negritud no es un movimiento de estilo o de ideas literarias. Es

Revista Iberoamericana, Vol. LXXIX, Núm. 243, Abril-Junio 2013, $559-575$
ISSN 0034-9631 (Impreso) 
algo más: es una fuerza militante que lucha en medio de una sociedad de piel blanca que se resiste a aceptar su igualdad con la del hombre de piel negra, discriminándola, explotándola"(119). Tal reconocimiento del valor ideológico del movimiento africano, sin duda, afectó su postura estética e influyó sus futuras elaboraciones literarias que pasaron a incorporar y a celebrar la Negritud como una de las referencias de la subjetividad nacional dominicana. De modo general, los ensayos representan una mirada hacia el afuera, una contemplación de la resistencia del pueblo negro en África, los Estados Unidos y el Caribe. Para Portalatín, ¿es la Negritud una filosofía que sirve para entender la identidad etno-cultural dominicana? No hay un pronunciamiento vigoroso politizado universal, en el mismo espíritu de celebrar la resistencia africana. Parece favorecer una versión de la propuesta que pueda acomodar la trayectoria transculturada de su nación. En su análisis, Cocco de Filippis confirma en la producción literaria de Portalatín un enorme orgullo de su herencia africana y un profundo reconocimiento del lugar central que tal herencia ocupa en la isla (Documents 104). Esta posición estética coincide con sus ensayos en Culturas africanas, los cuales parecen homenajear a activistas africanos y a los fundadores del movimiento sin proponer su adopción o contemplación dentro del canon nacional. Para Portalatín la nación dominicana es una nación mulata: "Yo amo esos recuerdos porque somos un pueblo mulato. Lo soy. Y me alegro de haber podido objetivar aún y rectificar mejor lo que con frecuencia los investigadores de gabinete repiten de Africa" (Culturas africanas 26). ${ }^{3}$

Portalatín crea un puente entre la Negritud y la mujer afro-dominicana al incluir en Culturas africanas una sección dedicada a dos esclavas libertas, Teodora y Micaela Ginés (121-136). Sus ensayos anteceden el trabajo hecho por la historiadora afro-dominicana Celsa Albert Batista (Los africanos 51-53) sobre una esclava llamada Micaela. Las dos parecen estar contemplando la misma figura. El proyecto ideológico de llenar el vacío cultural e intentar reconstruir la presencia y la influencia perdidas de la mujer negra en el pasado lejano sufre muchos impedimentos, principalmente una falta de registros absolutos y confiables. “¿MICAELA GINES, MITO O REALIDAD HISTÓRICA?” (Culturas africanas 133) es el comentario que hace emerger la problemática latinoamericana frente a la herencia afro-femenina; cuestionar su existencia concreta es la aflicción constante de cualquier discurso histórico, hecho que sigue inhibiendo su plena inclusión política como uno de los componentes que entran en juego en el momento fundacional de la nación. La intención de una reconstrucción histórica por parte de Albert Batista complementa la configuración poética de Portalatín de proponer descripciones de las mujeres famosas en la historia de la esclavitud. Albert Batista nos presenta a Micaela, como una negra ladina, esclava doméstica, una de las mujeres originales africanas y parte del éxodo forzado de África a Europa primero, después de Europa a Santo Domingo

3 También disponible en Cocco de Filippis (Documents 107).

$\begin{array}{llllll}\text { Revista Iberoamericana, Vol. LXXIX, Núm. 243, Abril-Junio 2013, } & \text { 559-575 } \\ \text { ISSN 0034-9631 (Impreso) }\end{array}$ 
llegando allí quizás antes de 1503. Valiente y atrevida, según la historiadora, le solicitó al gobernador la construcción de un hospital para "sus congéneres, quienes vivían en la orfandad social que genera la esclavitud" (Los africanos 52). A ella se le atribuye ser la gestora de la demanda que dio como resultado la creación del Hospital Nicolás de Bari del cual hoy quedan sólo las ruinas. Para Portalatín, investigar la historicidad de ellas es un complemento natural a su intención estética. Las esclavas Micaela y Teodora emergen como las dos primeras y originales figuras, entre las madres olvidadas del archivo de la nación. Confirma su largo interés en las Ginés por su talento como músicas. "Busquemos nuestras raíces. No hay color sin hombres sobre la tierra. Por ello, siempre que puedo, recuerdo a las dos negras esclavas y libertas dominicanas; de nombradía -entiéndase- sólo reclamamos su condición de MUJER y lo de DOMINICANAS. Y se nos ocurre algo exacto: las Ginés de Santiago de los Caballeros, esclavas y músicas, también rompieron barreras" (Portalatín, Culturas africanas 124).

Teodora y Micaela sólo van a poder ocupar su verdadero lugar icónico en la literatura nacional. Surgen dentro del discurso poético, el que fabrica una figura femenina contemporánea representativa de la mujer dominicana, retrato clásico de las tres razas. Tal trabajo es visible en el poema épico de Portalatín Yania Tierra, publicado en 1981. La presencia de Yania Tierra en la antología Sisters of Calibán: Contemporary Women Poets of the Caribbean incluye a Portalatín dentro del proyecto regional feminista que ha nutrido la literatura y el activismo de escritoras contemporáneas como Sherezada (Chiqui) Vicioso, Aurora Arias, Ángela Hernández e Ylonka Nacidit-Perdomo. Insertar estas voces dentro de una calibanidad femenina se ha mostrado útil para promover un movimiento de proporciones regionales, que rompiera con las limitaciones lingüísticas y étnicas implicadas en ser del Caribe anglófono, francófono, holandés, y español (Fenwick xvii-xxxvi). Tales identidades individuales convergen hacia la contemplación de una hermandad literario-caribeña que en nuestra contemporaneidad sigue impactando la literatura. Yania Tierra se desarrolla como un poema grandioso en estilo y contenido al transcurrir durante los siglos de la colonización y al situarse como homenaje a todas las mujeres oprimidas y triunfantes durante todos los siglos. El personaje femenino en el poema es a la vez histórico y contemporáneo, implica una lucha continua de autoafirmación en su determinación de asumir el poder en el espacio poético.

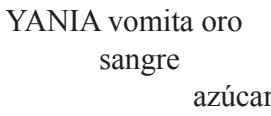

Sabe que la historia comienza en Marién

Con un cacique/luego dos/después todos/

Que los Encomenderos/ Los Repartimientos

Los indios/ los negros

Base de la Tragedia Humana/ Llamada Civilización [...] (56)

Revista Iberoamericana, Vol. LXXIX, Núm. 243, Abril-Junio 2013, $559-575$
ISSN 0034-9631 (Impreso) 
En su rol de observadora y protagonista principal Yania es la mujer antillana, representando la nación dominicana. De hecho, el poema recrea el camino de la conquista y la colonización pero en un espíritu poético modernizado que permite una focalización crítica.

YANIA observa

Se levanta ingenios/ se penetra su vientre

Se lava oro

Para los reinos de Europa Occidental [...] (78)

En el espacio poético Yania va a poder asumir varias formas, una de las cuales es la negra esclavizada, pero contradictoriamente, se rechaza tal posibilidad al mismo tiempo que se la contempla como historia, "Yania/Tierra/Esclava/ Jamás" (38). El lenguaje muestra a la mujer negra como figura colonizada y explotada pero al mismo tiempo hace trascender su condición al otorgarle un lugar en el discurso histórico.

Venden al abuelo y al padre de

Teodora y Micaela Ginés

Esclavas/ luego libertas en

Santiago de los Caballeros

Antes de 1580 residentes en Cuba

Las dos primeras damas músicas

$[\ldots]$

en aquel territorio (70)

MICAELA en La Habana

TEODORA en Oriente

Tocadoras de vihuela y de bandola [...] (Portalatín, 72)

$\mathrm{Al}$ reposicionar la figura femenina como elaboradora del discurso, la narradora asegura su dominio como contadora de la historia nacional. Es un formato estilístico que la sostiene en el centro de toda la elaboración textual. El poema se construye en contradicciones y desencuentros que trabajan en armonía para subvertir la fuerza negativa de la acción predominantemente masculina en la historia, y permitir la infiltración singular de un sujeto femenino, que, con determinación, ocupa el espacio histórico como actora e instigadora de todos los acontecimientos, una posibilidad anteriormente rechazada.

4 "Esclavas dominicanas libertas en un cuarteto antillano" (Portalatín, Culturas africanas 121-129) busca recuperar el relato olvidado de la trayectoria de dos esclavas talentosas, Micaela y Teodora.

Revista Iberoamericana, Vol. LXXIX, Núm. 243, Abril-Junio 2013, 559-575
ISSN 0034-9631 (Impreso) 
¿En Homenaje A Donna Summer?

The story, with its sentimental albeit hard-hitting unveiling of the psychological nuances of racism, is but one example of the depiction of the seeming impossibility of relations of sisterhood between black and white women, separated by class as well as by race. (Esteves y Paravisini-Gebert xxiii).

Hay momentos de esclarecimiento que confirman la existencia de una conciencia afro-feminista que choca con los ideales establecidos de la cultura nacional. En este sentido, se puede construir un nexo simbólico entre la crítica de Albert Batista frente a la marginación de la mujer afro-dominicana y Colita/Aurora, el personaje afro-americano en el cuento de Portalatín "La llamaban Aurora, pasión por Donna Summer". En Mujer y esclavitud en Santo Domingo, Albert Batista se fija en las expresiones culturales que impactan a la mujer negra (y al hombre negro) en la sociedad. Estos dichos populares, también cultivados por los medios masivos, expresan el sexismo y el racismo a la vez que, tal como se argumenta, pueden cargar una intención de cariño entre conocidos próximos. Las referencias sutiles "bien parecida", o "buena presencia" (157) confirman preferencias para las que no poseen un color de piel más oscuro; una sugestión de cuánto más blanca mejor, más bonita. En esta misma línea se encuentra "malo" apuntando "al pelo crespo que es de ascendencia negra" y su opuesto, "bueno" para el pelo lacio (157); de hecho los dos confirman una postura cultural que se alimenta en la noción de una superioridad racial asociada con el fenotipo blanco que, según el imaginario dominicano, representa status social, riqueza y prosperidad. Al mismo tiempo que Albert Batista afirma la identidad mulata de su nación, parece identificar una aflicción, resultado del rechazo de una estética fundamentalmente africana, concretamente visible en el mundo femenino en "el alaciarse el pelo desde la edad de infancia y en el uso exagerado de cremas blanqueadoras por doloroso que sea este proceso" (Mujeryesclavitud 158). SegúnAlbert Batista, el mulataje ha conducido a un rechazo a lo africano y lo negro. Las palabras "grampa, greña, pimienta, negra, prieta, haitiana" (Mujer y esclavitud 158) exprimen una asociación natural entre ser negro y el atraso cultural y el subdesarrollo, opinión que se verbaliza en "el negro cuando no lo hace a la entrada lo hace a la salida", "negra tenía que ser" o "si una persona considerada 'blanca' se une a un negro/a, retrocede la generación" (Mujer y esclavitud 158). La agresividad racista del discurso popular acaba siendo absorbida por el propio sujeto femenino que colabora en su propio abuso social, aumentando aún más el efecto negativo de esta alteridad en su cuerpo y cabeza, como confirmamos en "yo soy negra y fea, pero de mí nadie se burla" o "negra en mi casa, yo" (Mujer y esclavitud 162). La negra próspera o exitosa tampoco ha escapado a los efectos del desprecio: "Negra pero Licenciada" o "Es una negra que ha llegado donde no han llegado blancas" (Mujer y esclavitud 163). Albert Batista comenta la ineficacia en esta esfera de la perspectiva de Frantz Fanon y Aimé Césaire, de asociar la subjetividad

Revista Iberoamericana, Vol. LXXIX, Núm. 243, Abril-Junio 2013, $559-575$
ISSN 0034-9631 (Impreso) 
negra con lo bueno y lo bello. La lucha por abrazar la belleza en su Negritud es la base del trauma de Colita/Aurora, la niña en el cuento de Portalatín.

"LallamabanAurora, pasión por Donna Summer" tiene afinidad con la crítica cultural de Albert Batista en su forma de expresar un sentir profundo captado en la repetición constante de "No. Noo. Y noo. ¡No!” (15). Portalatín personaliza el dilema de la etnicidad al revelar el enojo e impaciencia de Colita, quien se siente manipulada y frustrada por tener que conformarse a expectativas impuestas por un mundo mayoritariamente blanco, que en nada estimula su desarrollo como joven mujer negra y orgullosa. Bajo los cuidados de Mrs. Sarah, Colita sufre un cambio de nombre a Aurora cuando fue a matricularse en la escuela. La niña se rebela porque el nombre Colita representa el último recuerdo que tiene de la madre. Mentalmente sigue existiendo como Colita, en feroz resistencia a los mandatos de aquella mujer blanca y autoritaria que la controla. Desde el inicio parece resistir el sistema y todo lo que representa - la escuela, las monjas, la disciplina, la matemática-, se siente en guerra. Desea abrazar su herencia negra, lo cual la hace vulnerable frente a los blancos que la marcan como diferente. Colita reconoce el racismo inconsciente implícito en cómo la ven y no lo tolera: "Ni acepto aquello, dale que dale de que Aurora es una negrita inteligente [...]" (14).

Colita no se interesa en ocupar la posición de la Otra que sirve de apoyo lógico a la visión restricta del negro como un ser apenas capaz de cantar y entretener a los blancos, razón por la cual establece una relación contradictoria con la música de Donna Summer. Por un lado la adora, por otro, tal música refuerza su estado de encarcelamiento que la mantiene amarrada a Mrs. Sarah, quien también ama la música, como todos los blancos. Por esto huye, pero huir no es escapar de la sociedad blanca que adora a Donna Summer, ni es cambiar su color, su pelo, su inteligencia. De hecho, ella no quiere rechazarse, quiere ampliar la visión que la sociedad tiene de ella, de Donna Summer:

La voz de Donna llena de nuevo la barra, el barrio, el pueblo. Trato de recogerme los cabellos moteados, duros, si nací con ellos así, así se quedan. Lo absurdo es que me discriminen y hagan alarde de mi sabiduría porque soy casi bachiller. No. Noo. Y, noo. ¡No! [...] Si yo fuera la Donna Summer recogiera todos los discos que se encuentran en las tiendas $[\ldots](15)$

El relato la muestra desde el dentro, revelando su rabia contra el maltrato y el desprecio de ser la "negrita fea" (15). Ella se siente explotada al mismo tiempo que mentalmente ataca a todos en un torrente emocional extremo. Pero todo está en la cabeza porque su realidad es seguir viviendo su desgracia. Encuentra un paralelo de su existencia atormentada en la casa de Mrs. Sarah en las noticias sobre el apartheid en Soweto y Johannesburgo. No está sola en su angustia y quizás por ahora consiga tolerar la música de Donna Summer (que Mrs. Sarah adora y siempre toca) por su manera de

\footnotetext{
Revista Iberoamericana, Vol. LXXIX, Núm. 243, Abril-Junio 2013, 559-575 ISSN 0034-9631 (Impreso) ISSN 2154-4794 (Electrónico)
} 
acompañar su llanto, pues llorar es lo único que puede hacer para llenar el vacío que la rodea y la derrumba.

EN NOMBRE DE TODAS LAS POETAS

La poesía de Portalatín no está sola sino que es parte de una rica tradición de antologías, compilaciones que apuntan hacia una conciencia negra literaria que resiste la trayectoria ideológica de la identidad nacional. Las temáticas referentes a la figura afro-femenina son utilizadas para registrar la trayectoria de ésta y su manejo del medio social. Hay múltiples posibilidades; la figura negra se diversifica, quizás incómoda en ciertos roles de madre, abuela, y despreciada, por ejemplo, en "El ombligo negro de un bongo" y "Cara Sucia" de Marianela Medrano (Fenwick 210). Igualmente merecedora de atención es "Elegía segunda" de Portalatín (Morrison 124-125) que demuestra cómo la maternidad y la madre patria se funden en una expresión poética que busca introducir un espíritu feminista dentro de una lectura racializada del medio cultural. En los versos, el espacio nacional multi-étnico sirve de contexto para retratar la condición económica precaria de la mujer negra. Lo que marcan los versos en las secciones de "Elegía segunda" tituladas "Mi madre fue una de las grandes mamá” y “¡Pobre negra!” es un espíritu de percepción y apreciación profundas que penetran los múltiples tejidos que la envuelven para revelarnos la operación interna de cómo piensa y cuáles son las posibilidades para que supere todas las dificultades y todas las presiones que la rodean. Su poder está en su sencillez y en la sabiduría de percibirla en las más diversas expresiones de sentimientos:

Mamá. Olimpia. Mamá. El público no debe por fundas de

ni frazadas y techos

alimentos

levantar estatuas. Deber de amor son esas cosas.

Deber del hombre por todos los HOMBRES.

[...]

-Lo cierto es -me explicó un psiquiatra-

que el recuerdo para ser correctamente asimilado

necesita estar pegado a un sentimiento de amor, gratitud, admiración, odio, sexo, o cualquier otro tema [...]

(Morrison, Aída 124-125)

Estas dos secciones de "Elegía segunda" emergen como un trabajo de concientización, a la vez que sirven para ampliar el valor de la figura afro-dominicana por medio de la idea de sus influencias interminables que trascienden todas las subsecuentes generaciones, que marcan a todos sus hijos. El deseo de la redención histórica de la mujer acompaña una postura nacionalizada de reconocer la diversidad étnica, una forma poética de promover la armonía nacional para no caer en la trampa estadounidense de represión racista y

Revista Iberoamericana, Vol. LXXIX, Núm. 243, Abril-Junio 2013, $559-575$
ISSN 0034-9631 (Impreso) 
segregación totalizadora en la modernidad. Al mismo tiempo, cualquier camino hacia una modernidad digna exige un enfrentamiento con las preocupaciones de conciencia nacional y no hay un asunto más trastornado que la cuestión de Haití:

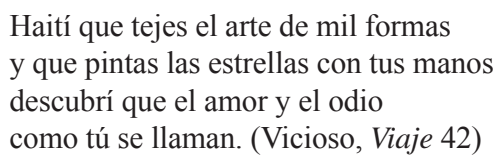

La herencia francófono-caribeña es innegable y la convicción es que el pueblo dominicano es parte de tal herencia, una creencia intrínsecamente visible en poemas como "Haití" (Vicioso, Viaje 42-3), "Flor de caña" (Vicioso, Un extraño ulular 43-44) y "Bien dans ma peau" (Vicioso, Un extraño ulular 58-59)..$^{5}$ En "Bien dans ma peau" el título francés revela el deseo de definirse más allá de la Hispanidad considerada la identidad unívoca desde la época de Trujillo e importante para propagar la ideología anti-haitiana. Al declararse orgullosamente en francés, la voz poética se está rebelando contra la política estatal de sentimiento anti-haitiano al mismo tiempo que, contrario a lo que se espera, expresa un amor y orgullo de su color de piel. El poema se mueve al contrario del deseo nacional, tornándose una metáfora de resistencia a lo esperado. El rechazo dominicano de la herencia negra se reemplaza con el abrazo de la Haitianidad. Ella se posiciona en sincronía perfecta con la identidad isleña, es dominico-haitiana, es caribeña. La evocación de la cultura francófona demuestra el deseo personal de abrazar este lado caribeño que, para muchos, es parte de lo que significa ser dominicano. No importa que no sea lengua nativa pues la configura como una expresión lingüística estratégica desde la mujer negra que experimenta emociones y afinidades con los afrodescendientes. Para declarar su Negritud procede a la escenificación de un espacio tropical, caribeño, colorido, poblado de gente, naturaleza, actividades que pueda corresponder a la ciudad regional. Los tipos, los olores, los colores, las frutas, la brisa y el movimiento nos ayudan aproximarnos a la musicalidad de vida y al alma de lo cotidiano.

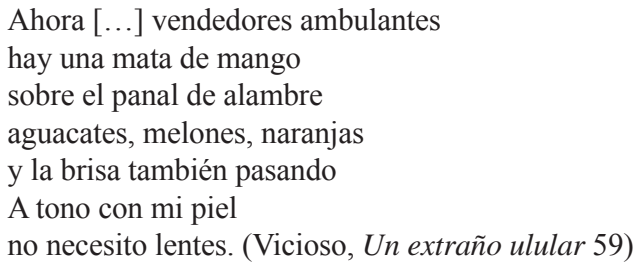

5 También consultar Roberts (176-177).

Revista Iberoamericana, Vol. LXXIX, Núm. 243, Abril-Junio 2013, 559-575
ISSN 0034-9631 (Impreso) 
Tal como lo desarrolla el poema, el lugar descrito puede ser un mercado dominicano, haitiano, trinitario o jamaicano, de hecho, no hay referencia específica, lo importante es el propósito del poema. No se busca una identidad, al contrario, se la retrata por los ojos de una narradora totalmente segura de su forma de ser y de expresarse. La poesía se siente, segura, firme, demostrando una fuerte identidad negra, afirmada en el momento actual. Una identidad negra y también eclécticamente caribeña. En nuestra discusión sobre la literatura dominicana, la poeta Ylonka Nacidit-Perdomo comentó el asunto dentro del país. ${ }^{6}$ Afirmó que trabajar temáticas negras y haitianas implicaba provocar una confrontación interna entre los intereses del Estado y la identidad africana, un camino politizado. En los tiempos del régimen trujillista se la visualizaba a la poeta como una disidente, opuesta a la dictadura y por esto altamente peligrosa. Admitió que bajo Trujillo la literatura canónica era muy elitista, se encuadraba dentro del proyecto civilizatorio y de avance industrial que era el sueño que el dictador tenía para su nación. La cuestión afro-género se aproximaba mucho a la cuestión de clase, en un estado en el cual la clase alta era blanca y la clase baja mulata o negra (clasificada oficialmente como "india"). Involucraba el tema de los trabajadores rurales de Haití, que cortaban la caña de azúcar y que habitaban bajo las condiciones más precarias en los bateyes. Como tema, no había posibilidad de celebrar, expandir, contemplar, investigar. En este contexto, podemos entender que la oposición por considerar una estética afro-dominicana cabía perfectamente dentro del propósito mayor de la nación que buscaba proyectar su superioridad etno-racial, su orgullo nacional y su dignidad soberana.

Valorar la cultura y la espiritualidad africanas es parte natural de la historia femenina. “Otoño negro" (Portalatín, Del desconsuelo 95) y "Memorias negras" (Portalatín, Del desconsuelo 111-115) vigorosamente condenan el racismo estadounidense mientras que "Bissau" (Vicioso, Viaje 25-26) trae memorias de la conexión profunda con el viejo continente. Las diosas del vudú dominicano Yemayá y Ochún aparecen en "Un extraño ulular traía el viento" y nos conducen hacia atrás en un espíritu contrario, deseoso de recuperar un conocimiento anterior, una conexión con el origen cultural. Las referencias poéticas se mezclan, produciendo una noción indefinida del lugar de origen, quizás sea un espacio africano, quizás caribeño. Son referencias a la vez históricas, pero también pueden ser recientes. En este poema, el mar establece una conexión intercontinental, indicando que la posibilidad de reconstrucción necesariamente tendría que incluir el estado anterior olvidado africano y el terrible viaje trasatlántico.

${ }^{6}$ En discusión literaria con Nacidit-Perdomo, en la Biblioteca Nacional de Santo Domingo, en julio de 2005.

Revista Iberoamericana, Vol. LXXIX, Núm. 243, Abril-Junio 2013,
ISSN 0034-9631 (Impreso) 


\section{CONCLUSIÓN}

La visibilización de una estética de Negritud como parte de la producción femenina dominicana sirve de punto de partida para examinar el lugar y el rol de esta escritura dentro de la esfera artística-cultural nacional. Es importante notar que de modo general la estética negra no juega un papel central en las elaboraciones literarias. La preferencia es identificar a la República Dominicana como una nación mulata (algunos prefieren decir "india") y las referencias históricas o artísticas demuestran la predisposición universal de ver la herencia negra como una de las tres líneas originales identitarias, esto confirma que el rechazo no es total, pero la Negritud será celebrada de una manera casi enajenada (como algo ajeno) como aquello que vino de África, como una forma de referirse a los distantes ancestros, a los Estados Unidos y, seguramente, a Haití. El proceso de anagnórisis del sujeto femenino negro como perteneciente a esa comunidad no se produce. Desde su percepción subjetiva asume una identidad que guarda relación con la Negritud pero no pone el acento en ello, es mucho más importante declararse mulato como nuevo tipo identitario que posee independencia de los tipos raciales que le dieron origen; hay que entender este fenómeno como un efecto del conflictivo contexto político de la época. Haití y República Dominicana no son lo mismo, las naciones encontraron en la adhesión a fenotipos raciales diferentes una forma estratégica de marcar diferencias: Haití es negra y República Dominicana, mulata.

Es importante notar un fenómeno en la actualidad, las estrategias empleadas por una literatura feminista que otorga una presencia más destacada a la figura afrofemenina situándola como protagonista. Tal postura literaria parecería posicionar esta poesía y prosa en confrontación con la cultura nacional dominicana de la cual forma parte. Hay un compromiso con las revelaciones históricas, un deseo de ser caribeña y una insistencia en combatir la injusticia y las desigualdades que siguen perturbando la existencia de tal sujeto en la isla. De hecho, el resultado final es la presencia de un discurso complementario de la Nación, uno que le recuerda a la nación que la mujer negra debe ser valorada por el lugar no sólo que ocupó en el pasado sino también en el presente. Esta literatura sutilmente le recuerda a la nación que no puede llegar a ser un proyecto acabado y pleno si deja de lado a uno de los grupos sociales que lo conforman y que han ayudado a hacer de ella lo que es. Uno de los grupos con quienes el Estado necesita realizar una reparación histórica. La República Dominicana no puede desconocer esto, allí están también sus archivos para recordárselo. Lo estratégico de esta literatura consistió en no construirse desde una postura contracultural. Este trabajo es un reconocimiento a ese grupo de escritoras que posibilitaron la valoración de la mujer negra desde el discurso literario dominicano. Ellas levantaron su voz para decirle a la nación que la literatura está allí para recordarle la deuda que tiene impaga con el sujeto afro-femenino.

\footnotetext{
Revista Iberoamericana, Vol. LXXIX, Núm. 243, Abril-Junio 2013, 559-575 ISSN 0034-9631 (Impreso) ISSN 2154-4794 (Electrónico)
} 


\section{OBRAS CITADAS}

Adams, Clementina R. Common Threads: Themes in Afro-Hispanic Women's Literature. Miami: Ediciones Universal, 1998.

ADOMUVI(Recopilación de la Asociación Dominicana de Mujeres Votantes). Perfil de la mujer dominicana ayer y hoy. Santo Domingo: Editora Universitaria UASD, 1992.

AlbertBatista, Celsa. Mujer yesclavituden Santo Domingo. Santo Domingo: INDAASEL, 2003.

Los africanos y nuestra isla. Santo Domingo: INDAASEL, 2001.

Álvarez, Virtudes. Mujeres del 16. Santo Domingo: Mediabyte, 2005.

Bankay, Anne Maria. "Crossing Boundaries: Race, Gender, Identity in Short Narrative Fiction by Women Writers of the Dominican Republic." Gendered Realities. Essays in Caribbean Feminist Thought. Patricia Mohammed, ed. Barbados: U of the West Indies P, 2002. 325-333.

Los africanos y nuestra isla. Santo Domingo: INDAASEL, 2001.

Cocco de Filippis, Daisy. “Aída Cartagena Portalatín: a Literary Life.” Desde la diáspora. A Diaspora Position. Daisy Cocco de Filippis, sel. New York: Ediciones Alcance, 2003. 191-206.

Compilación, bibliografía, e introducción. Documents of Dissidence. Selected Writings by Dominican Women. Nueva York: CUNY Dominican Studies Institute, 2000.

Díaz, Tomás Báez. La mujer dominicana. Santo Domingo: Editora Educativa Dominicana, 1980.

"Dominicanas meritorias: doce calles con sus nombres en un homenaje permanente". El País. 26 marzo 2003: 15-16.

Esteves, Carmen C., y Lizabeth Paravisini-Gebert. Introduction. Green Cane and Juicy Flotsam: Short Stories by Caribbean Women. Carmen C. Esteves and Lizabeth Paravisini-Gebert, eds. New Brunswick, NJ: Rutgers UP. xi-xxvi.

Fenwick, MJ. "Introduction." Sisters of Calibán. Contemporary Women Poets of the Caribbean. MJ Fenwick, ed. Falls Church, VA: Azul Editions, 1996. Xvii-xxxvi.

Gutiérrez, Franklin. Evas terrenales. Bibliografías de 150 autoras dominicanas. Santo Domingo: Ediciones FERILIBRO, 2000.

Howard, David. Coloring the Nation. Race and Ethnicity in the Dominican Republic. Oxford: Signal, Lynne Rienner, 2001.

Lebrón de Anico, Rosa. La mujer en la gesta heroica de la Independencia Nacional. Santo Domingo: Búho, 2000.

Morrison, Mateo ed. Aída Cartagena Portalatín - Selección Poética. Santo Domingo: Mediabyte, 2000.

Nacidit-Pardomo, Ylonka. Entrevista personal. Santo Domingo, julio 2005.

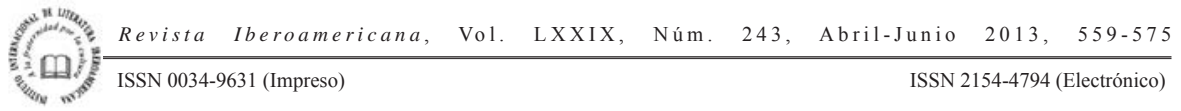


Portalatín, Aída Cartagena. Culturas africanas rebeldes con causa. Santo Domingo, República Dominicana: Ediciones de la Biblioteca Nacional, 1986.

Del desconsuelo al compromiso. From Desolation to Compromise. A Bilingual Anthology of the Poetry of Aida Cartagena Portalatín. Daisy Cocco de Filippis. ed. Santo Domingo, Taller, 1988.

Escalera para Electra. Santo Domingo: U Autónoma de Santo Domingo, 1970. "La llamaban Aurora (Pasión por Donna Summer." Tablero. Doce cuentos de lo popular a lo culto. República Dominicana: Editora Taller, 1978. 11-17.

Yania tierra. Poema documento - Document Poem. 1971. Washington D.C.: Azul Editions, 1995.

Roberts, Nicole. Main Themes in Twentieth-Century Afro-Hispanic Caribbean Poetry. A Literary Sociology. Lewiston, Queenston, Lampeter: The Edwin Mellen Press, 2008.

Rodríguez Guglielmoni, Linda M. y Judith Kerman. "Introduction." Praises \& Offenses: Three Women Poets from the Dominican Republic. Aida Cartagena Portalatín, Ángela Hernández Nunez, Ylonka Nacidit-Perdomo. Judith Kerman, trad. Rochester, NY: BOA Editions, 2009. 9-17.

Rondón, Pura Emeterio. Estudios críticos de la literatura dominicana contemporánea. Santo Domingo: Editora Búho, 2005.

Solano, Patricia y Altagracia Ortiz Gómez, compilación y redacción. Mujeres de febrero $3^{\mathrm{a}}$ ed. Santo Domingo: Secretaria del Estado de la Mujer, 2005.

Solano, Patricia. "1965. Las mujeres también hicieron abril”. Santo Domingo: Secretaria de Estado de la Mujer, s.a. 1-6.

Stevens-Acevedo, Anthony R. "La dominicanidad itinerante". Desde la orilla: hacia una nacionalidad sin desalojos. Silvio Torres-Saillant, Ramona Hernández, Blas R. Jiménez, eds. Santo Domingo: Ediciones Librería La Trinitaria, 2004. 147-162.

Vallejo, Catharina. "Innovación, calidad y riqueza en la cuentística dominicana femenina contemporánea". Mujeres como islas. Antología de narradoras cubanas, dominicanasy puertorriqueñas. Santo Domingo, La Habana: Ediciones FERILIBRO, Ediciones Unión, 2002. 89-102

Vicioso, Sherezada. Un extraño ulular traía el viento. Santo Domingo: Editorial Alfa y Omega, 1985.

Viaje desde el agua. Santo Domingo: Ediciones Visuarte, 1981.

Revista Iberoamericana, Vol. LXXIX, Núm. 243, Abril-Junio 2013, 559-575 ISSN 0034-9631 (Impreso) 
